\title{
Effect of COVID-19 vaccination on menstrual periods: a retrospective cohort study
}

\author{
Victoria Male ${ }^{1}$ \\ ${ }^{1}$ Imperial College London
}

December 13, 2021

\begin{abstract}
Objective. Clinicians and regulators are receiving reports of changes to menstrual periods following COVID-19 vaccination. However, it is unclear if the two are biologically linked. If they are, people using hormonal contraception are predicted to be less likely to report a change and spontaneously cycling people vaccinated prior to ovulation more likely. The objective was to test these hypotheses. Design. Retrospective cohort study. Setting. UK. Population. 1273 people who had received at least one dose of a COVID-19 vaccination, have periods or withdrawal bleeds and keep a record of the dates of these. Methods. Participants reported whether they use any hormonal contraception and, for each dose of the vaccine, on which day of their menstrual cycle they were vaccinated and details of how the timing and flow of their next period compared to their normal experience. Main outcome measures. Association between 1. the use of hormonal contraception and reported changes to timing or flow of the next menstrual period, and 2. the timing of vaccination within the menstrual cycle and reported changes to timing or flow of the next menstrual period. Results. The data from this cohort did not support the pre-specified hypotheses that people using hormonal contraception would be less likely to report a change, or that spontaneously cycling people vaccinated prior to ovulation would be more likely to report a change. Conclusions. This study did not detect strong signals supporting the idea that COVID-19 vaccination is linked to menstrual changes in most people. Funding. No specific funding.
\end{abstract}

\section{Hosted file}

Manuscript_10_12_2021.docx available at https://authorea.com/users/451003/articles/549253effect-of-covid-19-vaccination-on-menstrual-periods-a-retrospective-cohort-study 
A
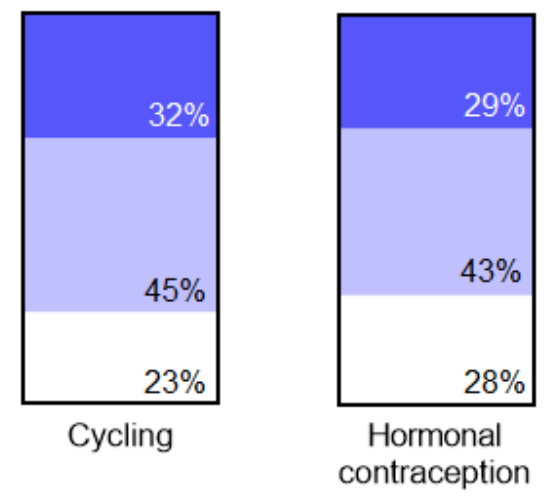

$\square$ Earlier than usual

口 On time

$\square$ Later than usual

Cycling

contraception

B

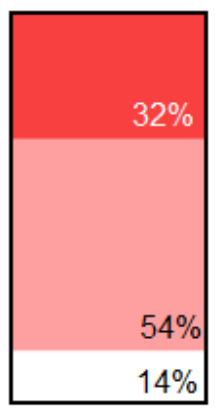

Cycling

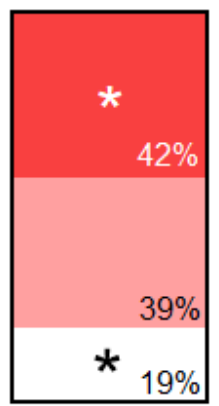

Hormonal contraception $\square$ Lighter than usual

$\square$ The same as usual

$\square$ Heavier than usual

$p^{\prime}=0.001$ 

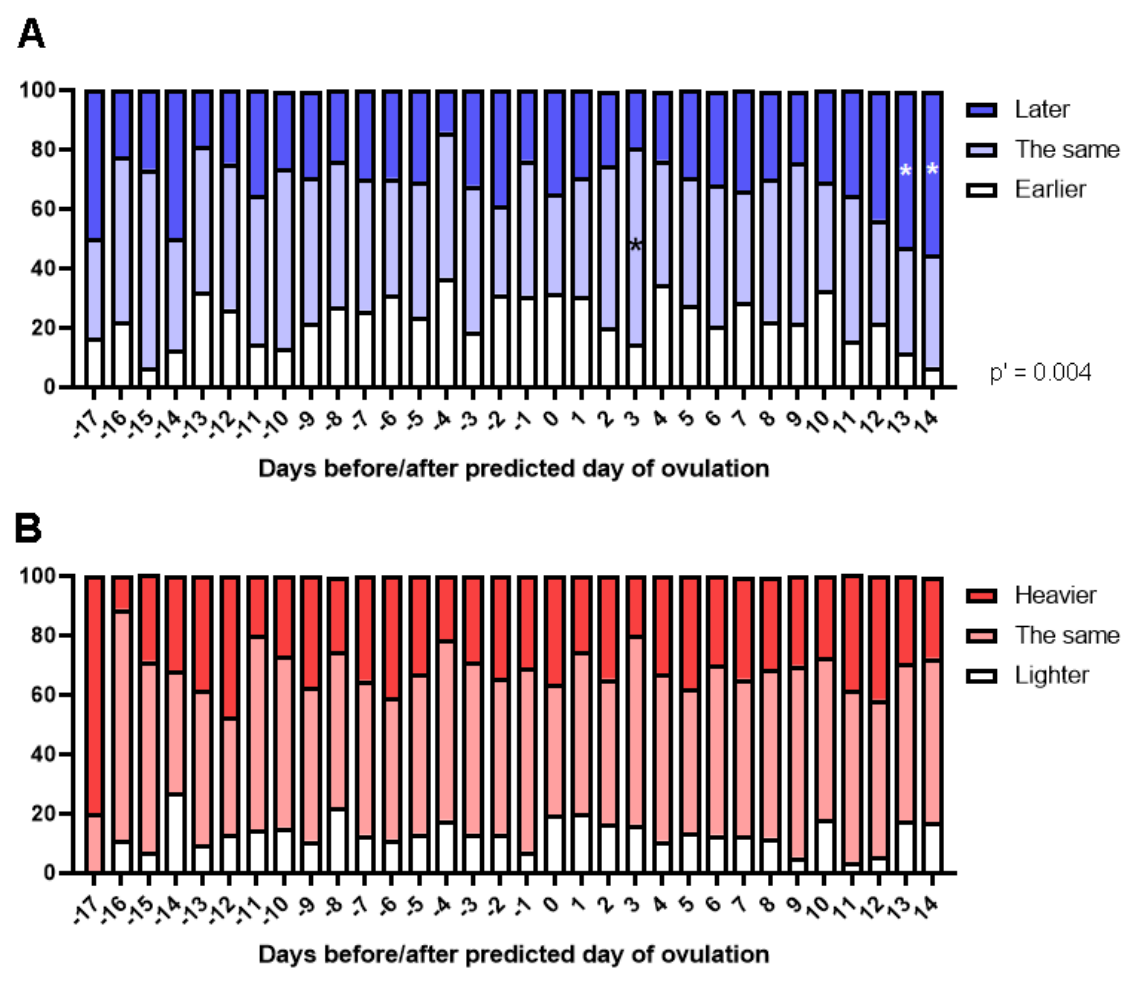
A

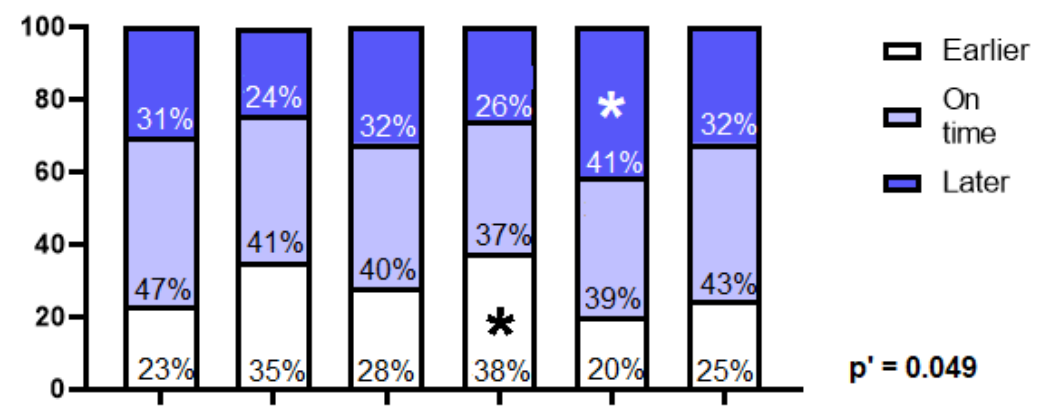

B

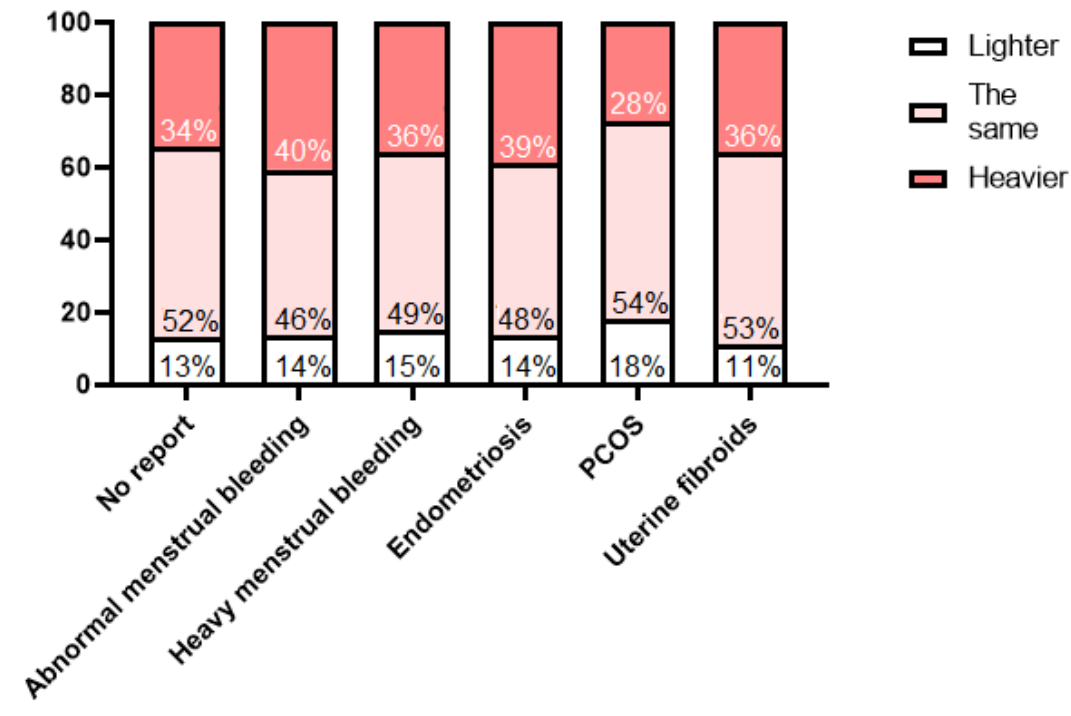

